\title{
Linseed Oil Based Amide as Corrosion Inhibitor for Mild Steel in Hydrochloric Acid
}

\author{
Z.N. Yang, Y.W. Liu, Y. Chen ${ }^{*}$ \\ College of Chemistry \& Chemical Engineering, Binzhou University, Binzhou, Shandong 256600, \\ China \\ *E-mail: chen123yu123@163.com
}

doi: $10.20964 / 2018.01 .94$

Received: 6 August 2017 / Accepted: 27 September 2017 / Online Published: 1 December 2017

\begin{abstract}
A new inhibitor named linseed oil amide (LOA) has been synthesized. The molecule structure of LOA was characterized with Fourier transform infrared spectroscopy and its inhibition behavior for mild steel in hydrochloric acid was measured by weight loss, potentiodynamic polarization, electrochemical impedance spectroscopy (EIS) and scanning electron microscopy. Weight loss measurements reveal that the corrosion rate was dependent on the concentration of the inhibitor, which decreases with increasing the LOA inhibitor concentration. Both of the anodic and cathodic are inhibited according to the potentiodynamic polarization results, while the cathodic effect is more pronounced, which indicates that the LOA inhibitor acts as a mixed-type with predominant control of cathodic reaction. The adsorption of LOA onto mild steel in hydrochloric acid follows Langmuir adsorption isotherm. Activation parameters are calculated and discussed, which imply the endothermic nature of the mild steel dissolution process and the adsorption of LOA inhibitor acts mainly as chemisorptions. The inhibition efficiency is still over $90 \%$ after immersion of $96 \mathrm{~h}$, suggesting the long-term effective property of LOA inhibitor.
\end{abstract}

Keywords: inhibition; mild steel; EIS; hydrochloric acid

\section{FULL TEXT}

(C) 2018 The Authors. Published by ESG (www.electrochemsci.org). This article is an open access article distributed under the terms and conditions of the Creative Commons Attribution license (http://creativecommons.org/licenses/by/4.0/). 